\title{
Situación y retos de la cooperación española para el fortalecimiento de las instituciones públicas
}

\author{
PABLO BANDEIRA GREÑO \\ Departamento de Economía Aplicada, UNIVERSIDAD CEU SAN PABLO, ESPAÑA. E- \\ mail: pbandeira@ceu.es
}

ARTURO WARLETA GONZÁLEZ
Presidente de la ONGD FUNCIONA, ESPAÑA. E-mail: arturo@funciona.org.es

\begin{abstract}
RESUMEN
Este artículo analiza la situación y los retos actuales de la cooperación española en materia de fortalecimiento de las instituciones públicas. En primer lugar, tratamos de definir a qué nos referimos con el concepto de "fortalecimiento de instituciones públicas", frente a la idea de "aumento de recursos organizativos". En segundo lugar analizamos la importancia cuantitativa que la cooperación española otorga a este tipo de acciones basándonos principalmente en la base de datos del Seguimiento PACI 2010. Después pasamos al estudio de las principales fortalezas y debilidades de nuestra cooperación en este sector, partiendo de entrevistas semiabiertas llevadas a cabo con personal técnico de tres organismos públicos de cooperación y de 17 ONGD, así como de las evaluaciones realizadas por la Dirección General de Planificación y Evaluación de Políticas de Desarrollo. El artículo termina con una serie de conclusiones y recomendaciones para que la ayuda española en este sector sea más efectiva.
\end{abstract}

Palabras clave: Cooperación al desarrollo, fortalecimiento institucional, gobernanza, España.

\section{Situation and Challenges of Spanish Foreign Aid for Better Governance}

\begin{abstract}
This article analyzes the situation and the current challenges of Spanish development assistance aimed at public institutional development. First, we try to define what we mean by the concept of "public institutional development", as against the idea of "increasing organizational resources". Secondly we analyze the quantitative importance of Spanish cooperation granted to such actions based mainly on the 2010 PACI tracking database. Then we the main strengths and weaknesses of our cooperation in this sector, on the basis of semi-open interviews carried out with technical personnel of three public cooperation agencies, $17 \mathrm{NGO}$ and the evaluations carried out by the DirectorateGeneral of planning and evaluation of development policies. The article ends with a series of conclusions and recommendations for the Spanish aid in this sector to be more effective.
\end{abstract}

Keywords: Development Assistance, Institutional Development, Governance, Aid, Spain.

Clasificación JEL: F35, H10

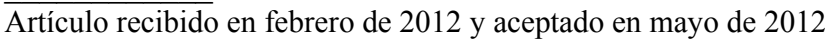

Artículo disponible en versión electrónica en la página www.revista-eea.net, ref. ə-30304 


\section{INTRODUCCIÓN}

El fortalecimiento de las instituciones públicas (FIP) es abanderado por las agencias internacionales de desarrollo como uno de los principales frentes a abordar en la cooperación para la promoción de un desarrollo humano sostenible en el tiempo (BM, 1998; CE, 2006; DFID, 2006; PNUD, 1997; USAID, 2008). En el Plan Director de la Cooperación Española aún vigente (20092012), el Gobierno de España establece la promoción de los derechos humanos y de la gobernabilidad democrática -termino que como veremos se usa de forma sinónima al FIP- entre las prioridades horizontales de la cooperación española. Según este plan, "el enfoque de gobernabilidad democrática como prioridad transversal implica orientar todas las actuaciones de la Cooperación Española hacia la profundización del régimen democrático y el Estado de Derecho y un desempeño del Estado más eficaz, en términos económicos y sociales". Además, la primera prioridad sectorial mencionada en el plan es asimismo la gobernabilidad democrática (Gobierno de España, 2009). Podemos ver por lo tanto que el FIP es considerado como uno de los principales caballos de batalla tanto por las principales agencias internacionales como por la cooperación española.

Si bien en otros artículos hemos profundizado en el intenso debate sobre la asignación de la ayuda en relación a la calidad de las instituciones del gobierno o el Estado receptor (Bandeira, 2009a y 2012), en este artículo queremos tratar de lograr tres objetivos complementarios: (1) aclarar el concepto y la importancia del fortalecimiento institucional, ya que se está usando con diferentes acepciones que dificultan mucho la profundización y el debate en el tema; (2) analizar la importancia cuantitativa que la cooperación española otorga a este tipo de acciones, así como los principales organismos financiadores, canalizadores y receptores de esta ayuda; y (3) detectar los principales retos de la cooperación española en este área.

Para el primer objetivo nos hemos basado en la literatura científica internacional que trata directamente sobre los efectos de las instituciones sobre el desarrollo a largo plazo. Para el segundo, hemos utilizado el último informe de seguimiento PACI publicado, que incluye una base de datos que resume y clasifica todas las operaciones de cooperación internacional llevadas a cabo con financiación pública española durante 2010 (DGPOLDE, 2011) ${ }^{1}$.

Para detectar los principales retos de la cooperación española en materia de FIP, hemos partido del marco conceptual expuesto sobre qué implica fortalecer

\footnotetext{
${ }^{1}$ En este artículo sólo hemos querido hacer una estimación del peso de la ayuda española dirigida al fortalecimiento de las instituciones públicas, con los datos más recientes, de cara a ilustrar su importancia actual. Como extensión de este trabajo, sería interesante analizar los datos de varios años para evaluar su evolución cuantitativa.
} 
una institución pública, así como de dos aspectos clave relacionados con la eficacia de la cooperación en general, según la Declaración de Paris y la Agenda de Accra para la Acción (OCDE, 2005 y 2008): la necesidad de que la ayuda sea transparente y de que los proyectos establezcan los resultados objetivamente verificables que se pretenden alcanzar con la intervención. Partiendo de este marco, hemos llevado a cabo entrevistas con personal técnico de las tres principales agencias públicas españolas de cooperación que financian actividades de FIP, y de 17 ONGD (Organizaciones No Gubernamentales para el Desarrollo). Las entrevistas han sido de tipo semiabierto, de cara a indagar también sobre la percepción que tienen los propios agentes sobre los principales retos que encuentran para promover el FIP a través de sus organizaciones. Además, hemos tratado de sintetizar las principales lecciones aprendidas que figuran en las evaluaciones de proyectos de FIP publicadas por la Dirección General de Planificación y Evaluación de Políticas de Desarrollo (DGPOLDE). Por último, el artículo indica las principales conclusiones y recomendaciones que se derivan de los resultados obtenidos.

\section{EL CONCEPTO Y LA IMPORTANCIA DEL FORTALECIMIENTO DE LAS INSTITUCIONES PÚBLICAS}

Para poder analizar las actividades de la cooperación española relacionadas con el "fortalecimiento institucional", debemos aclarar antes la definición de este concepto. Para ello, como es común en muchas vertientes académicas, es necesario revisar sus orígenes en la literatura anglosajona al respecto. En este sentido, encontramos muchos términos, más o menos sinónimos, que han surgido en los últimos años. Los más conocidos son "buena gobernanza o gobernabilidad" (good governance), desarrollo institucional (institutional development), construcción estatal (state building) y estados desarrollistas (developmental states). El término "good governance" es sin duda el más utilizado en la literatura inglesa sobre cooperación internacional. En español, los términos más conocidos son "fortalecimiento institucional", "gobernabilidad democrática" y "buen gobierno".

Pero, ¿a qué se refieren todos estos términos? Según la definición clásica de North (1990) las "instituciones" son las reglas de juego que determinan las restricciones y los incentivos en las interacciones que se producen en la sociedad. Estas reglas o instituciones pueden ser informales (tradiciones, códigos de conducta, cultura) o formales (leyes y normas privadas con validez jurídica, como los estatutos de una empresa o de una asociación). Unas instituciones regulan el funcionamiento del Estado (instituciones públicas o del sistema público) y otras regulan el funcionamiento de los mercados (instituciones económicas). Ejemplos de instituciones formales políticas son las constituciones, las leyes electorales y las leyes que regulan el funcionamiento del parlamento, el sistema 
judicial y el sistema de empleo público. Ejemplos de instituciones formales económicas son el derecho mercantil y laboral, las leyes de competencia, las de defensa del consumidor, etc. En este artículo nos ocuparemos exclusivamente de la cooperación española para el fortalecimiento de las instituciones formales públicas.

Es importante notar aquí que la costumbre de denominar también instituciones a las organizaciones no se corresponde con el concepto tal y como se configura en el debate internacional. En esta literatura se distingue claramente entre "instituciones", como reglas de juego, y "organizaciones", como agrupaciones de personas que se unen para lograr un objetivo común. Las organizaciones, de hecho, están compuestas por recursos (humanos, financieros y físicos) y por instituciones (reglas de juego formales e informales). Por lo tanto, de cara a fortalecer cualquier tipo de organización, como por ejemplo un Estado o una empresa, se debe tratar de aumentar y mejorar la calidad de sus recursos, y se debe tratar de mejorar sus reglas de juego o instituciones.

Lo que precisamente destaca abundante literatura científica de las últimas dos décadas es que, si bien los recursos son necesarios para que las organizaciones se desarrollen, aún más importante es que se "fortalezcan" sus instituciones (ver por ejemplo North, 1990; Acemoglu, Johnson y Robinson, 2001; Easterly y Levine, 2003; Rodrik, Subramanian y Trebbi, 2004). Dicho de manera sencilla, de poco o nada vale inyectar recursos a un Estado o a una empresa, si no existen unas instituciones o reglas de juego que promuevan el esfuerzo, la innovación, la honestidad y la cooperación. Según los principales economistas a nivel mundial, el disponer de instituciones que promuevan este tipo de actitudes es probablemente el principal factor que explica el desarrollo económico a largo plazo de los países ${ }^{2}$.

A lo largo de este artículo nos centraremos pues en esta concepción de la literatura internacional sobre las "instituciones", por lo que descartaremos acciones de cooperación que, en el ámbito español, se han denominado también de "fortalecimiento institucional", pero que se refieren al aumento o mejora de la calidad de los recursos de las organizaciones. Ejemplos típicos son proyectos de formación de personal o de dotación de equipos informáticos para organismos públicos. Este tipo de acciones sería mejor denominarlas si se quiere de "fortalecimiento de recursos organizativos".

Una vez definido el concepto de "institución", nos queda por definir qué entendemos por "fortalecimiento" o "desarrollo" institucional. Y para ello, tene-

\footnotetext{
${ }^{2}$ Además de las referencias clásicas mencionadas, se puede mencionar el informe elaborado por la Comisión sobre Crecimiento y Desarrollo que reunió el trabajo de cientos de economistas y políticos de prestigio a nivel mundial entre 2006 y 2008, en el que se determina que "el gobierno no es la causa próxima del desarrollo...pero un gobierno estable, honesto y efectivo es crítico en el largo plazo" (Comission on Growth and Development, 2008 p. 4-5).
} 
mos que responder a la pregunta de si existen o no instituciones más "buenas" o más "fuertes". Aplicado al sector público, las instituciones "fuertes" son aquellas que promueven el desarrollo económico y social de un país, medido mediante indicadores como el PIB per cápita, los niveles de pobreza o el Índice de Desarrollo Humano. Pero, ¿existen instituciones públicas universalmente fuertes o buenas? Si bien no existe aún un consenso absoluto a la hora de responder esta pregunta, sí que existe tanto evidencia empírica suficiente como un consenso casi universal de que instituciones públicas que provean un sistema judicial-policial independiente y eficaz, un sistema de empleo público meritocrático, una administración pública transparente, y la libertad y pluralidad de asociación y expresión, son instituciones que promueven el desarrollo humano a largo plazo, y por lo tanto, instituciones "fuertes" (ver Rauch y Evans 2000; Bruneti y Weder, 2003; La Porta et al, 2004; Norris, 2007; y las referencias de agencias internacionales mencionadas al comienzo de la introducción). Por lo tanto, a lo largo de este artículo, se denominará "fortalecimiento de instituciones públicas" a todas aquellas acciones que promuevan leyes y reglamentos del sistema público más transparentes, más meritocráticas, más estables y con más contrapesos y balances ${ }^{3}$.

\section{ANÁLISIS CUANTITATIVO DE LA AYUDA ESPAÑOLA AL FORTALECIMIENTO INSTITUCIONAL}

De acuerdo a los datos del año 2010 -últimos disponibles cuando se redacta este artículo-, el total de ayuda oficial al desarrollo (AOD) gastado por España fue de 4.491 millones de euros, lo que supuso un $0,43 \%$ de nuestra Renta Nacional Bruta (DGPOLDE, 2011).

La financiación de esta ayuda establece una considerable diversificación de agentes canalizadores (ver Figura 1), siendo el gobierno central el principal actor con diferencia $-88 \%$ del total de AOD en el año 2010- seguido, muy de lejos, por las Comunidades Autónomas, que financiaron un 9\% de la AOD española total.

En cuanto al agente canalizador de la AOD española en su conjunto, según podemos apreciar en la Tabla 1, la cooperación multilateral acapara más de la mitad de toda la AOD. La ayuda canalizada por las ONGD supone el 15\% del total. Asimismo, el importe medio de los proyectos canalizados por ONGD no alcanza los 95.000 euros, mientras que tanto los multilaterales como como los bilaterales directos superan los 160.000 euros de media.

\footnotetext{
${ }^{3}$ Para una discusión completa sobre instituciones y desarrollo, ver Bandeira (2009b).
} 
Figura 1

Distribución de la AOD española en 2010 según agente financiador (millones de $€$ )

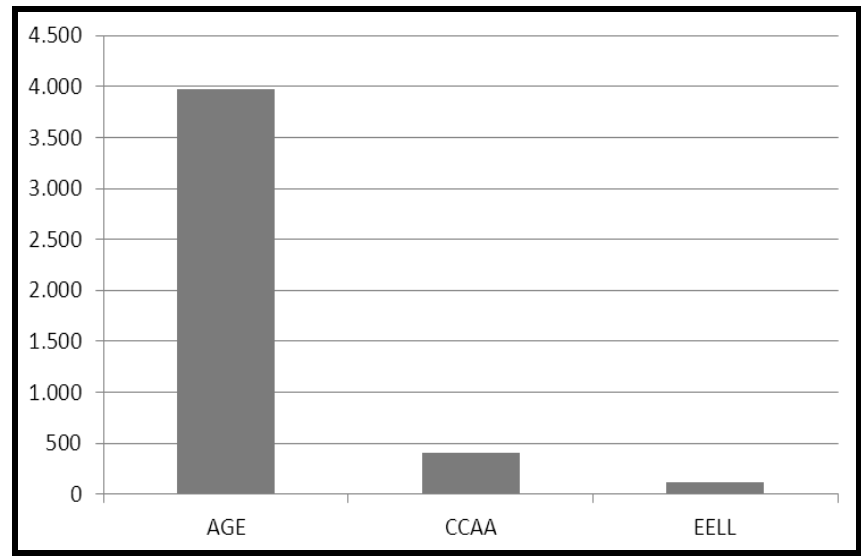

Fuente: DGPOLDE (2011).

Tabla 1

Distribución de la AOD española en 2010 según agente canalizador

\begin{tabular}{|l|c|c|}
\hline \multicolumn{1}{|c|}{ Canalización } & Millones de Euros & \% valor \\
\hline Multilateral & 2.483 & 55 \\
\hline Bilateral directa & 1.368 & 30 \\
\hline Vía ONG & 641 & 15 \\
\hline
\end{tabular}

Fuente: DGPOLDE (2011).

Como última clasificación de la AOD total, podemos desglosar los datos según la región destino de la ayuda, tal y como se observa en la Figura 2. África es el destino que más fondos recibió en 2010 , con más de un $40 \%$ de la AOD total, siguiéndole América Latina, con aproximadamente un tercio de la ayuda.

De cara a analizar la cooperación española cuyo principal objetivo es el fortalecimiento institucional, algunos estudios parten de los datos de ayuda clasificados en el sector 150 de la OCDE, denominado Gobierno y Sociedad Civil, que es donde intuitivamente se enmarcarían este tipo de proyectos. No obstante, muchas intervenciones enmarcadas en otros sectores (como pueden ser educación, salud, etc.), están dirigidas principalmente a fortalecer las instituciones y políticas públicas de dichos sectores, por lo que cabría considerarlos 
dentro de este estudio. Para ello, hemos confeccionado una selección específica de subsectores de la OCDE que se puede consultar en el anexo ${ }^{4}$.

Figura 2

Distribución de la AOD española según destino en 2010

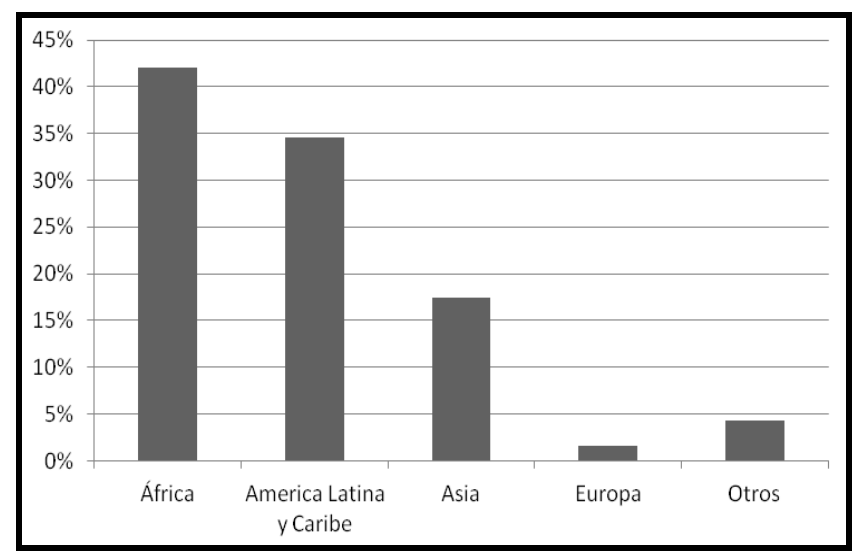

Fuente: DGPOLDE (2011).

De los 32.477 proyectos de cooperación financiados públicamente en 2010, 9.922 corresponden a estos subsectores, lo que supone un 30\%. En términos económicos, la cuantía correspondiente a estos proyectos suma 1.412 millones de euros, un $31 \%$ del total de la AOD española ${ }^{5}$.

En cuanto a la canalización de estas ayudas, los fondos destinados se reparten en porcentajes similares a la AOD total, aunque ganando peso las contribuciones multilaterales, a costa principalmente de las bilaterales directas (ver tabla 2). En nuestra opinión esto es adecuado, ya que las acciones de fortalecimiento institucional requieren normalmente de mayor legitimidad por parte del agente de cooperación, que puede ser mejor justificada por un organismo multilateral que por el gobierno de un país donante.

\footnotetext{
${ }^{4}$ Como se puede observar en el anexo, esta selección incluye principalmente los subsectores del grupo 150 -exceptuando la retirada de minas (sector 15250)- junto con los subsectores relativos a "política y gestión administrativa" con los que suele comenzar cada sector. La descripción de estos subsectores CRS es: "Política de \{sector], planificación y programas; ayuda a ministerios de \{sector], la administración y los sistemas de gestión; asesoramiento y fortalecimiento institucional; gestión y buen gobierno de centros del \{sector]; desarrollo planes del \{sector]; actividades del [sector] sin especificar.

${ }^{5}$ Utilizando el mismo criterio de clasificación, los proyectos de FIP supusieron en 2009 un 25\% de la AOD total española (DGPOLDE, 2010).
} 
Tabla 2

Distribución de la AOD española en 2010 a subsectores de FIP según canalizador

\begin{tabular}{|l|c|c|}
\hline \multicolumn{1}{|c|}{ Canalización } & Euros & \% valor \\
\hline Multilateral & 950.064 .778 & 67 \\
\hline Bilateral directa & 283.616 .932 & 20 \\
\hline Vía ONG & 178.298 .713 & 13 \\
\hline
\end{tabular}

Fuente: DGPOLDE (2011).

La canalización multilateral incluye en su mayoría aportes a fondos multilaterales, especialmente a las diferentes agencias de Naciones Unidas. Los de mayor importe (aquellos que superan los 10 millones de euros) son destinados al funcionamiento ordinario de dichos organismos, o a la celebración de cumbres o seminarios. Destacan aportes como los 45 millones para financiar la Conferencia de las partes del Protocolo de Kyoto. También superan esa cuantía algunas contribuciones al presupuesto de la Comisión Europea para la Cooperación al Desarrollo.

Observamos, pues, que en un mundo cada vez más globalizado, donde la agenda viene en gran medida dada por los entes supranacionales, ya sean estos gubernamentales (como la Comisión Europea) o entidades estrictamente dedicadas al desarrollo, la financiación se adecúa a esos compromisos, siendo dedicada a la contribución de España en estos organismos.

En relación a la distribución de AOD total según financiador, la Administración General del Estado aumenta ligeramente su participación en la financiación de proyectos de FIP ( $91 \%$ del total), disminuyendo ligeramente la proporción de financiación de las Comunidades Autónomas (7\%).

En cuanto a las regiones receptoras de ayuda, el principal continente receptor es África, seguido de cerca por América Latina (ver Figura 3). Comparándolo con la distribución de la AOD total española, de puede ver que América Latina gana en preponderancia, mientras que África pierde ligeramente. Esto también se puede justificar, ya que probablemente tiene más sentido enfocar la ayuda para el FIP en una región más desarrollada y cercana jurídicamente a España como América Latina, que en África ${ }^{6}$.

Por último, de cara a centrar la atención sobre el perfil de proyectos concreto al que atiende este estudio, hemos filtrado aquellos financiados de forma directa (cooperación bilateral directa) y cuya contraparte sea un organismo público. Obtenemos 666 proyectos, con un presupuesto total de 132 millones de euros.

\footnotetext{
${ }^{6}$ El apartado denominado "otros" crece notablemente cuando se selecciona la AOD a subsectores de FIP, debido a que una gran cantidad de este tipo de ayuda tiene como destino a los países en vías de desarrollo en general.
} 
Obviando los proyectos ejecutados en el área latinoamericana, que veremos a continuación, identificamos los cuatro que alcanzan o superan los 3 millones de euros, y analizamos los diferentes datos que la tabla de seguimiento PACI aporta sobre ellos, especialmente su descripción e indicadores.

Figura 3

Distribución de la AOD española a subsectores de FIP según destino en 2010

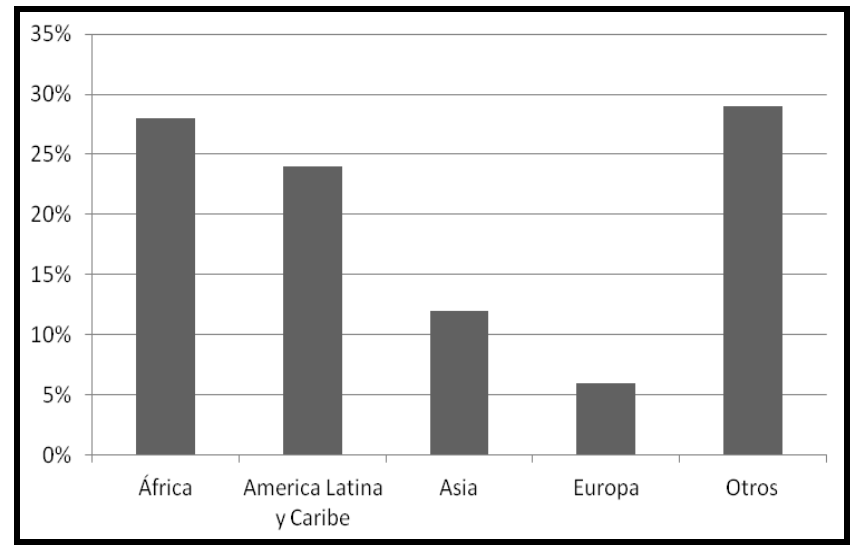

Fuente: DGPOLDE (2011).

Los cuatro proyectos consisten en apoyos presupuestarios sectoriales, para los Ministerios de Salud de Marruecos, Etiopía y Filipinas, y para el de Medio Ambiente de Cabo Verde. Sólo el primero de los mencionados incluye un listado detallado de los indicadores para medir su eficacia (número de pacientes tratados, aumento de la cobertura en las regiones más desfavorecidas, etc.). Para el resto no figuran indicadores de resultados esperados.

A continuación analizamos, con los subgrupos seleccionados, los fondos destinados a América Latina y cuya contraparte sea una institución pública. Dicho filtro nos arroja 487 proyectos ejecutados (completa o parcialmente), con un presupuesto de 74 millones durante el año 2009, siendo los países de la región centroamericana (con la excepción de Honduras) los principales destinatarios. Si seleccionamos ahora las ayudas que superan el millón de euros, para ampliar el estudio en lo relativo al área latinoamericana, obtenemos una muestra de nueve proyectos. De ellos, cinco se refieren explícitamente a apoyo presupuestario, tanto en los frecuentes sectores de salud y educación como un aporte al presupuesto de la Policía Nacional de Nicaragua.

Resulta interesante, de cara a calibrar el impacto esperado de los proyectos, hacer mención a los indicadores reflejados en esta muestra. En dos de los nueve proyectos no figuran. Otros dos se encuentran en negociación. Dos más remiten 
a estrategias de la contraparte, mencionando en general la mejora de su calidad. Los tres restantes hacen alusión a indicadores numéricos, aunque sólo dos establecen metas (reducción de la impunidad en un $2 \%$, y asistencia de los beneficiarios a las formaciones).

Como podemos ver, los indicadores de nuestros aportes pocas veces expresan numéricamente los resultados que pudieran clasificarse como satisfactorios, $\mathrm{y}$ cuando lo hacen se refieren a menudo al número de funcionarios que han recibido capacitaciones. Sin embargo, en ciertos casos (como la reducción del 2\% de la impunidad) sí se fijan metas cuantificables y relacionadas directamente con el objetivo, como los tiempos medios en tramitar alguna función pública, o el impacto en indicadores nacionales.

\section{ANÁLISIS CUALITATIVO DE LA COOPERACIÓN ESPAÑOLA PARA EL FORTALECIMIENTO INSTITUCIONAL DE ORGANIZACIONES PÚBLICAS}

Antes de pasar a describir los resultados obtenidos tanto de las entrevistas como del análisis de las evaluaciones de proyectos financiadas por la DGPOLDE, hemos considerado conveniente comentar los principales motivos que entendemos justifican el papel de la cooperación española en el área del fortalecimiento de las instituciones públicas.

\subsection{Justificación del rol de España en materia de cooperación para el FIP}

Existen ciertas ventajas comparativas, comúnmente aceptadas, que pueden justificar la cooperación española en esta materia:

1. El rápido crecimiento de los fondos españoles destinados a cooperación en los últimos años. Este aumento ha convertido a nuestro país en un donante a tener en cuenta en los debates internacionales, más allá de nuestro tradicional nicho latinoamericano. Además, parte de estos fondos se han destinado a cubrir estudios de extranjeros en nuestro país, lo que ha estrechado lazos académicos y técnicos.

2. Procesos reconocidos internacionalmente como exitosos, como nuestra reciente transición, el crecimiento sostenido de la economía durante tres décadas, la descentralización gubernamental o nuestra participación en la integración europea. Además, existen multitud de marcos legales, especialmente en América Latina, inspirados en nuestra legislación.

3. El avance en ciertos derechos civiles, que constituyen para muchos sectores liberales de otros países ejemplos en los que basarse.

4. Específicamente en América Latina, los obvios lazos existentes entre nuestro país y dicho continente, en ámbitos como el idioma, cultura, ne- 
gocios e incluso familiares. La creciente inmigración ha facilitado en ocasiones la retroalimentación de experiencias.

Éstos son, entre otros, factores que constituyen nuestro "poder blando", o legitimidad para las acciones de política exterior, así denominado en contraste con los poderes económico o militar.

A día de hoy, sin embargo, la crisis económica está motivando una reconsideración de los éxitos obtenidos en España en su propio proceso de FIP, sobre todo en términos de sostenibilidad. La intuitiva respuesta a este cuestionamiento es compartir experiencias de las que obtener lecciones sin caer en paternalismos o imposiciones de modelos.

\subsection{Los principales retos de las agencias gubernamentales con especial protagonismo en cooperación para el FIP}

Como hemos visto, en el caso español, la Agencia Española de Cooperación Internacional para el Desarrollo (AECID) es uno de los actores protagonistas de las actuaciones de FIP, tanto en calidad de financiador como, en ocasiones, canalizador. También destaca la participación de la Dirección General de Planificación y Evaluación de Políticas de Desarrollo (DGPOLDE), y de la Fundación Internacional y para Iberoamérica de Administración y Políticas Públicas (FIIAPP).

Para realizar este estudio hemos mantenido entrevistas con personal técnico de los tres organismos ${ }^{7}$. Entre los funcionarios entrevistados hay una amplia aceptación del último Plan Director de nuestra cooperación, que vence el año 2012. No obstante, indican que la realidad de las acciones emprendidas dista significativamente de las intenciones en el papel. Además de tradicionales debates, como los diferentes grados de divergencia propuestos entre nuestra cooperación y nuestra agenda política y económica, surge frecuentemente en estos tiempos la irónica autocrítica sobre el propio fortalecimiento institucional de la cooperación española; esto es, numerosos trabajadores del sector público han visto aumentadas sus responsabilidades debido al rápido incremento de fondos destinados a cooperación, sin que las estructuras, especialmente la AECID, haya sido reforzada de manera acorde.

La AECID es una Entidad de Derecho Público adscrita al Ministerio de Asuntos Exteriores y de Cooperación a través de la Secretaría de Estado de Cooperación Internacional (SECI). Es, como establece la Ley 23/1998, de 7 de julio, de Cooperación Internacional para el Desarrollo, el órgano de gestión de

\footnotetext{
${ }^{7}$ Para el estudio se realizaron entrevistas a tres trabajadores de AECID, dos de DGPOLDE y dos de FIIAPP.
} 
la política española de cooperación internacional para el desarrollo. Cuenta entre sus referencias más relevantes con los siguientes proyectos de FIP $^{8}$ :

- Contribución al Fondo español para la financiación de proyectos y actividades del Sistema de Integración Centroamericano (20,5 M€)

- El Programa Iberoamericano de Formación Técnica Especializada (PIFTE), con más de $10 \mathrm{M} €$

- El Apoyo Presupuestario a la Red Solidaria en El Salvador (4 M€)

No nos ha sido posible obtener evaluaciones de estos proyectos ${ }^{9}$. Analizando el Seguimiento PACI 2009, sí resaltamos que el primero está orientado al fortalecimiento de la integración centroamericana, cuya conveniencia política y económica está debidamente justificada. Sin embargo, el seguimiento PACI no muestra actividades, resultados o indicadores para este proyecto.

El segundo proyecto es, fundamentalmente, formación a trabajadores públicos latinoamericanos, y es gestionado por la Organización de Estados Americanos. El resultado que señala se limita a "Capacitación técnica de funcionarios de las administraciones públicas iberoamericanos que redunde en el fortalecimiento institucional". La equiparación de formación con fortalecimiento institucional es aún frecuente, aunque los planes de actuación diferencian cada vez más ambos conceptos.

En cuanto al tercero, Apoyo Presupuestario a la Red Solidaria en El Salvador, incluye resultados esperados, pero se limita a una declaración de intenciones, sin objetivos numéricos: "Mejorados ingresos de familias en extrema pobreza contribuyendo a la erradicación del hambre y vinculándolo a protocolos de salud y educación; Fortalecida oferta de servicios básicos en salud, programas nutricionales y educación básica; Mejorada infraestructura social básica..."

Es de señalar, según la percepción de los implicados por ambas partes, que las condiciones en materia de monitoreo y evaluación que la AECID impone a las ONGD suelen ser mucho más estrictas que las que aplica la agencia a las contrapartes públicas como gobiernos nacionales y organismos multilaterales, independientemente de los mayores volúmenes que supone cada proyecto.

Continuando con la DGPOLDE, esta dirección general también forma parte de la SECI. Su mandato principal es el de llevar a cabo la planificación y las evaluaciones de las políticas de cooperación españolas. Publican evaluaciones de proyectos ejecutados o financiados por la AECID.

\footnotetext{
${ }^{8}$ Algunos ya mencionados en el análisis cuantitativo

${ }^{9}$ En la página web del SICA hemos podido encontrar la Memoria de Labores y un resumen de los principales logros alcanzados. No obstante, en ninguna de estos dos documentos se indican los resultados alcanzados. Simplemente se describen las actividades realizadas.
} 
La DGPOLDE ha publicado 28 evaluaciones (accesibles desde la página Web del MAEC), además de informes sobre el rol de la cooperación española en conjunto en determinados países. Una vez revisadas estas evaluaciones, constatamos que en los proyectos de FIP se repiten frecuentemente los siguientes problemas ${ }^{10}$ :

- Fuga de cerebros tras recibir la formación. A menudo, la calidad técnica de las formaciones es suficientemente avanzada como para motivar la movilidad de los funcionarios al sector privado, ya sea como empleados, consultores o emprendedores. No se observan cláusulas en los proyectos de compromiso de permanencia por parte del funcionario, ni de voluntad de retener a los empleados por parte de la entidad beneficiaria. Dicho de otra manera, hay una escasa repercusión de estos proyectos en el fomento de la construcción de carreras técnicas de funcionarios o en la meritocracia.

- Aunque entre las evaluaciones más antiguas y las más recientes podemos detectar mejoras en la diferenciación de indicadores de resultados respecto a indicadores de productos, es necesario avanzar en la comprobación de los primeros. Por ejemplo, se siguen clasificando como indicadores de resultados de un proyecto el número de alumnos que han participado o de clases impartidas, los cuales no son resultados (efectos), sino productos o actividades del proyecto

- El establecimiento adecuado de la línea de base y la capacidad de aislar los efectos del proyecto siguen siendo muy mejorables. La frontera en ocasiones la ponen los medios para recopilar los datos necesarios que aporten la información de los resultados (los indicadores objetivamente verificables). En el caso de los impuestos, una mayor y más justa recaudación sería el objetivo último, pero aislar los resultados del proyecto sería una tarea complicada.

- En ocasiones, equipamientos o software excesivamente sofisticados corren el riesgo de dejar de ser utilizados en el momento en que desaparecen los capacitadores. Además, se evidencia un excesivo énfasis en la informatización, sin tener en cuenta una visión global de los procesos burocráticos, cuya interrelación provoca que el ritmo de la institución en su conjunto sea el del eslabón más lento. En este sentido, se indica que para

${ }^{10}$ Para el estudio se han revisado las 28 evaluaciones existentes, con especial énfasis en aquellas que evalúan proyectos más ligados al sector de FIP: Fortalecimiento Municipal en Flores (Guatemala), Reforma Judicial en Bolivia, Desarrollo integral de Cotacachi (Ecuador), Fondo de ayuda al equipamiento en Iberoamérica, Programa de Cooperación Interuniversitaria en Iberoamérica y el Programa de desarrollo local y fortalecimiento municipal en Honduras (Del Álamo, Guijarro y Visuales, 1998; DGPOLDE, 1999, 2000 y 2002; SEINTEX, 2002; UIM, 2005). 
obtener resultados sostenibles es necesario hacer un diagnóstico organizacional completo de la unidad pública o departamento beneficiario, pero los fondos no suelen ser suficientes para realizarlos.

- Los conocimientos adquiridos recaen más en las personas que en las instituciones, siendo poco frecuente la inclusión de las formaciones en manuales internos de la institución. Uno de los factores que desalienta ese refuerzo es la ventaja de los capacitados, a quienes interesa monopolizar los conocimientos.

- En muchas ocasiones la evaluación se limita a las percepciones de los beneficiarios en entrevistas, quienes suelen alabar los proyectos para no perder financiación futura.

- A menudo se pretende cambiar una situación jurídica injusta realizando exclusivamente tareas de sensibilización con la población beneficiaria, sin tomar en cuenta la necesidad de que éstos establezcan cauces de incidencia política.

Además de las recomendaciones que se pueden extraer de estos problemas, se señalan también otros problemas, válidos para las acciones de cooperación en general, pero sobre los que han incidido los responsables de las evaluaciones:

- Hay que atender en mayor medida a los procesos evolutivos de las contrapartes, para quienes a menudo el proyecto se queda escaso de tiempo.

- El rendimiento y sostenibilidad de los proyectos se incrementa cuando los beneficiarios son cofinanciadores.

- Una evaluación de impacto adecuada debe incluir, además de un análisis al finalizar el proyecto, otro a largo plazo, como pudiera ser a los 5 años.

La FIIAPP (Fundación Internacional y para Iberoamérica de Administración y Políticas Públicas), por su parte, no es una institución pública como tal, sino una fundación del sector público estatal, pero cuya normativa se rige por el derecho privado. Es especialmente relevante en el campo que nos ocupa, ya que, de acuerdo a su visión, "aspira a convertirse en el action tank de referencia en el sector de la gobernabilidad democrática, promoviendo y acompañando los procesos de desarrollo en los países y regiones donde actúan la Cooperación Española y europea".

Respecto a la información que hemos recabado sobre los trabajos que viene realizando la FIIAPP en este sector, de acuerdo a su memoria de actividades y a las entrevistas mantenidas con tres empleados de la misma, esta entidad confía en una mayor superación en breve de la identificación de formación con FIP. En estos momentos se encuentra en preparación el PAS (Plan de Acción Sectorial) relativo a gobernabilidad. No obstante, ya se han publicado algunos (como agua o medio ambiente) que incluyen subsectores relacionados con el FIP. 
En general, la FIIAPP entiende su especialidad como una versión amplia de la formación a individuos, englobando seminarios, talleres participativos, study tours, y asistencias técnicas, ya sean de corta o larga duración. Éstas últimas incluyen los twinings, muy frecuentes en la cooperación de la Comisión Europea, que incluyen la estancia de un funcionario español en el país beneficiario, donde tiene ocasión de estudiar con cierto detalle el funcionamiento de la institución en cuestión, y la recepción en su homóloga española del funcionario que recibe la asistencia. Si bien estas asistencias gozan de una buena concepción, no están exentas de los problemas que hemos mencionado según las evaluaciones de la DGPOLDE.

La FIIAPP aporta proyectos significativos en sus referencias sobre este sector. Destaca el proyecto EUROsociAL, financiado por la Comisión Europea y centrado en la cooperación técnica para promover la cohesión social en América Latina, a través del intercambio de experiencias entre administraciones públicas en los sectores de la Justicia, la Educación, el Empleo, la Fiscalidad y la Salud. La FIIAPP coordina el proyecto en su conjunto y lidera el componente de Justicia.

Dentro de EUROsociAL se enmarcan proyectos, más limitados geográfica y sectorialmente, que responden al concepto que manejamos de proyecto tipo de FIP. Así, la FIIAPP desarrolló un proyecto de justicia en Argentina, para el establecimiento de una Ley del Menor en el país, donde la justicia está descentralizada. Mediante la inclusión de representantes de los tres poderes, se consiguió instaurar dicha ley, que hoy está vigente.

El personal de la FIIAPP también menciona el debate sobre la interdependencia entre la política (término a menudo confundido con el partidismo) y la cooperación, donde surge en ocasiones la queja de recibir un público meta ya definido desde las autoridades locales o desde nuestros diplomáticos en el exterior, sin atender al interés técnico. Esto se refleja en frecuentes proyectos orientados a los funcionarios del país receptor de la ayuda, en los cuales, quien finalmente recibe una formación resulta ser un cargo político, con un interés y potencial más limitado en las cuestiones que verse la formación. La existencia de billetes transatlánticos y dietas suponen un incentivo que los máximos representantes no dejan filtrar a los subordinados.

Aun reconociendo este problema, los proyectos de FIP no mejoran en gran medida cuando se consigue que el funcionario técnico objetivo sea el receptor de las formaciones, ya que muchos países de América Latina siguen renovando la totalidad de los mandos intermedios con cada cambio de gobierno, lo que impide la retención del conocimiento por parte de las instituciones beneficiarias. De cara a solventar estos inconvenientes, se están incluyendo iniciativas como la presente en el Proyecto Municipia de la FIIAPP, donde toda formación que afecte al funcionamiento de las instituciones contrapartes ha de ser incluido en 
sus propios manuales. Esto supone la aceptación por parte de la contraparte de nuevos procedimientos operativos, lo que, en nuestra opinión, es buen síntoma de que se está promoviendo un fortalecimiento institucional real.

Otro inconveniente que señalan algunos técnicos de la FIIAPP es la dispersión de metodologías de gestión y/o monitoreo, que a veces se da incluso en el mismo proyecto. Además, el sempiterno dilema en cooperación de llegar en ocasiones a vender nuestro sistema como idóneo es más acentuado en la esfera de lo público. Así, a las posibles injerencias que definen dónde y cuánto aportar, se suma la subjetividad de la exposición de un modelo propio. La frontera entre compartir experiencias y convencer de las bondades de nuestro modelo es por supuesto difusa, pero ha de tenerse en cuenta su existencia en todo proyecto de FIP. Para ello, tal y como se ha señalado arriba, es necesario contar con una identificación exhaustiva, que asegure que el proyecto es lo que demanda y necesita el organismo, antes de ofrecer simplemente lo que sabemos hacer y/o lo que a unos altos cargos les conviene para aumentar su currículo.

Un ejemplo ilustrativo de esta cuestión es la descentralización. Una exposición parcial del modelo descentralizado en España, y la rapidez con la que se esgrime para la solución de problemas de muy diferente índole, ofrece un mensaje contradictorio a la institución receptora, que sufre en sus propias carnes los efectos negativos de la multiplicidad de agentes españoles al recibir a donantes estatales, autonómicos y locales, en detrimento de la eficiencia de los escasos recursos existentes (ocupación del tiempo, diferentes exigencias en justificación, etc.).

No obstante, es indiscutible el papel en materia de cooperación que están ofreciendo los agentes de la cooperación descentralizada. Podemos poner como ejemplo, dado su volumen y su especialización en FIP, el proyecto MEGODELPRO, siglas de Modelo Euro-Latinoamericano de Gobernanza Local para el Desarrollo Productivo. Se trata de un programa promovido por el Ayuntamiento de Alcorcón que cuenta con un presupuesto de 2,1 millones de euros, cuyo grueso es financiado por la Unión Europea.

Este proyecto pretende fomentar el desarrollo productivo mediante la generación de nuevas empresas, especialmente vinculadas a las iniciativas de economía social. Las actuaciones se llevan a cabo en Paysandú (Uruguay), Pimampiro (Ecuador), Valparaíso (Méjico) y Curahuara de Carangas (Bolivia). Las actuaciones para la generación de nuevos desarrollos productivos se llevan a cabo atendiendo especialmente a la concertación social con los agentes económicos y sociales de estos territorios, el fomento de la cultura emprendedora, y la conformación de redes de colaboración con su población inmigrada. Entre sus resultados esperados destacan pactos sociales, manuales de procedimiento, y la creación de unidades específicas en los ayuntamientos. 


\subsection{Las ONGD en la cooperación para el FIP}

Para la elaboración de este apartado se han llevado a cabo entrevistas semiabiertas en profundidad con personal de 17 ONGD españolas ${ }^{11}$. Se les ha pedido información de los proyectos relacionados con FIP que ejecutan, los problemas con los que suelen encontrarse, y los retos del sector.

En relación a los proyectos bilaterales directos de AOD, las ONGD tienden lógicamente a seleccionar contrapartes privadas, generalmente organizaciones de la sociedad civil del país receptor. Cuando las actividades son claramente clasificadas por la ONGD como propias de un proyecto de fortalecimiento institucional, éstas suelen estar más centradas en ayudar a canalizar la demanda de buen gobierno por parte de sus contrapartes. Así, los entrevistados enumeran un significativo número de proyectos de incidencia política para que las contrapartes presionen a sus gobiernos para la aprobación de leyes sociales (fundamentalmente, sobre educación y salud).

Las ONGD españolas están más enfocadas en América Latina que las entidades gubernamentales. Tienden a realizar proyectos más asistencialistas en África, y tratan de profundizar más en promover la participación política ciudadana en la región latinoamericana. Esta especialización es consciente y argumentada, alegando una mayor organización de la sociedad civil en América.

Las principales carencias que se encuentran en las actividades de cooperación para el FIP de las ONGD son: (1) la elevada preponderancia todavía de actividades meramente formativas o informativas, a las que les falta mecanismos explícitos de incidencia en la toma de decisiones políticas; (2) la falta aún generalizada de indicadores objetivos de resultados que se pretenden alcanzar con los proyectos; y (3) la ausencia generalizada de actividades de FIP en proyectos que no son específicamente de FIP, que, como hemos argumentado en el marco conceptual, serían necesarias para garantizar la sostenibilidad a futuro de los resultados.

Además, la mayoría de las ONGD españolas no tiene una política corporativa, sino que dependen en gran medida del enfoque de cada proyecto. En este sentido, los casos en los que las acciones están más enfocadas en cambios institucionales se deben en ocasiones a las imposiciones de las contrapartes, lo cual no deja de ser motivo de optimismo. Así, se da el caso de alguna ONG local que exige que al menos el $20 \%$ del presupuesto del proyecto se destine a modificar las causas últimas del problema que atiende, normalmente vía incidencia política para obtener cambios en las leyes.

11 Acción contra el Hambre, Cáritas, CIDEAL, CIECODE, COPADE, Cruz Roja Española, Fondo de Cooperación Hispano-Peruano, FUNCIONA, Fundación Philippe Cousteau, FUNDEMUCA, FUNDESO, Humanismo y Democracia, IEPALA, MPDL, Save the Children, Solidaridad Internacional, Unimos. 
La percepción de la ONGD española oscila entre la defensa de atenerse a la formación y la sensibilización, por los problemas derivados de una mayor injerencia en el país receptor, hasta el abstenerse de trabajar en ciertos contextos de alta corrupción, confiando expresamente en que la negativa de destinar fondos en dichos países o regiones sirva de presión para provocar cambios internos por parte de la sociedad civil. Esta estrategia asume que tanto el gobierno local como su sociedad civil recibirán un mensaje por parte de las ONGD, basado en la inexistencia de unas mínimas condiciones para llevar a cabo intervenciones en el país, que puede contribuir a la movilización como demanda interna de buen gobierno. En áreas donde existe una dilatada experiencia trabajando con los grupos de poder locales, se reconoce frecuentemente cierta aversión al riesgo que supone cuestionarlos, en pro de la ejecución sin incidentes de los proyectos.

Sin embargo, las ONGD también realizan un ejercicio de autocrítica en este sentido, reconociendo que hay un desfase entre lo que se vende en la sociedad del país donante, donde se defiende que los trabajos conllevarán un cambio de estructuras, con el discurso que se lleva al país receptor, donde se evita cualquier matiz que sugiera injerencia. Este doble rasero es en ocasiones trasladado al financiador, fundamentalmente la AECID, quien, de acuerdo a la percepción de algunas ONGD, insiste en la necesidad de una mayor repercusión en las instituciones, sin darle la prioridad real suficiente en sus propias intervenciones.

Otras ONGD defienden su escasez de iniciativas de cooperación para el FIP, ligando este concepto al de promoción de los derechos humanos, y esgrimiendo que algunas ONGD están muy especializadas en ese ámbito, y son ellas y solo ellas quienes debieran intervenir en ese sentido. En su consideración, se separan claramente las ONGD que buscan avances en democracia y gobernanza, como Amnistía Internacional, con las que ofrecen un trabajo más técnico, ya sea en sectores de salud, educación, etc. Como ya hemos comentado, este argumento es muy cuestionable, ya que la sostenibilidad suele requerir la incidencia en los gobiernos locales para cubrir las necesidades en el largo plazo.

La teoría ideal para promover cambios institucionales es común a la mayoría de ONGD: acompañar y asesorar a las organizaciones locales en los cambios favorables que ellas deciden llevar a cabo. En nuestra opinión, si bien esta idea es coherente con la noción de "apropiación" presente en la Declaración de París, no elimina la responsabilidad que tienen las ONGD de los países donantes de buscar y apoyar organizaciones locales que quieren promover cambios institucionales a favor de la democracia, la transparencia, la separación de poderes, la pluralidad de expresión, etc.

Cuando tratamos el área latinoamericana, las ONGD recuerdan que, en muchas ocasiones, el trabajo que pueden desempeñar en FIP está ya hecho. Lo demuestra, en su opinión, que el marco legal de muchos países del continente 
está incluso más avanzado que el de algunos países donantes. Lo que pasa, dicen, es que estas leyes muchas veces no se cumplen. Esta realidad, no obstante, más que justificar la inacción en cuanto a la cooperación para el FIP, devuelve el frente de batalla al modo de materializar los cambios (a la necesidad de que exista demanda local por el cambio) y a profundizar en cómo se pueden mejorar aquellas instituciones que deben garantizar el cumplimiento de las leyes (el enforcement). Es decir, indagar cómo se pueden mejorar las instituciones que afectan por ejemplo a la independencia y eficacia de la acción fiscal, judicial y policial.

Por último, mencionar que el creciente escepticismo existente sobre el mérito del progreso en Europa o EEUU, acentuado por la coyuntura actual, está motivando que muchos agentes de la cooperación estén incluyendo en sus proyectos las experiencias aprendidas de las economías emergentes, siendo Brasil un nuevo referente institucional para el ciudadano latinoamericano. Por ejemplo, las iniciativas de presupuestos participativos de este país se están tratando de replicar en otros países de la región.

\section{CONCLUSIONES Y RECOMENDACIONES}

En este artículo hemos tratado de analizar la situación y los principales retos actuales de la cooperación española en materia de fortalecimiento institucional de las organizaciones públicas (FIP), partiendo de la literatura académica y los grandes acuerdos internacionales, y de la percepción de los propios agentes de la cooperación española. En primer lugar, hemos visto que existe aún una notable confusión del término, principalmente en referencia a actividades de fomento de recursos organizativos, como la formación y la dotación de equipos, que no son propiamente instituciones. Partiendo de la literatura científica, sólo podemos hablar de fortalecimiento institucional cuando se produce un cambio en las normas y los procedimientos (tantos formales como informales) organizativos, que mejoren la capacidad de alcanzar los objetivos de dichas organizaciones. En el ámbito de los Estados, estamos hablando de cambios en las leyes y en la cultura política que mejoran la eficacia, la eficiencia, la transparencia y la legitimidad del sector público.

De cualquier forma, el FIP o la gobernabilidad democrática es asumido como caballo de batalla en el discurso de la cooperación española, observándose también un importante peso cuantitativo en la financiación de este sector (hemos estimado que un $31 \%$ del gasto total de AOD española en 2010 se dirigió a actividades de FIP) y, de acuerdo a las declaraciones de los funcionarios, con tendencia a aumentar ${ }^{12}$. De forma similar al conjunto de nuestra AOD, el

${ }^{12}$ Tal y como se comenta en la introducción, sería interesante hacer un análisis de la evolución del peso de la ayuda dirigida al fortalecimiento de las instituciones públicas en los últimos años. En nuestro caso, hemos realizado la comparación con datos de 2009, estimando que au- 
grueso de estas actuaciones se ejecuta a través de organismos multilaterales, lo que en nuestra opinión parece ser adecuado, ya que éstos tienen en principio mayor legitimidad para llevar a cabo actividades de FIP, que suelen ser delicadas, por considerarse que pueden conllevar injerencia en los asuntos propios del país de destino. Hemos visto también que nuestros proyectos de FIP se están ejecutando principalmente en América Latina y África, y que lo que más se hecha en falta es el establecimiento de metas objetivas con estas intervenciones, algo que por otra parte es común todavía a la mayoría de nuestras acciones de cooperación.

En el análisis cualitativo hemos tratado de profundizar sobre cuáles son los principales retos a la hora de mejorar el impacto de nuestra cooperación para el FIP. En el caso de la cooperación multilateral y bilateral directa española, los principales problemas que se plantean son:

- La falta de fortalecimiento institucional en las propias agencias de la cooperación española, unida a la crisis actual que está sufriendo España, nos resta legitimidad como actores para promover este tipo de acciones, tanto en los organismos multilaterales como en los países receptores de ayuda.

- El aprendizaje es muy complicado si persiste la opacidad del sistema español de ayuda, donde es muy difícil conseguir los formularios de los proyectos y sus informes finales.

- La aún extendida identificación del fortalecimiento institucional con actividades de formación e inversión en equipos y software informático, que no toman en cuenta las necesidades institucionales (los procedimientos formales e informales) de los organismos receptores. Esto hace que los resultados de estas intervenciones queden altamente cuestionados, debido a la fuga del personal formado o a la permanencia de procedimientos que actúan de cuello de botella.

- Falta generalizada de evaluación de resultados de estos proyectos, debido a que no se elabora una línea de base ni se establecen metas concretas a alcanzar, con indicadores objetivos.

- Sigue estando extendida la práctica de vender nuestro modelo institucional español como el mejor o como la única alternativa existente.

menta del 25 al 31\% entre 2009 y 2010. Esto, unido a la opinión de los expertos consultados, parece indicar que cada vez será más importante. No obstante, en 2010, y cuando se llevaron a cabo las entrevistas (finales de 2011), aún no se había producido el anuncio de la disminución drástica de recursos de cooperación al desarrollo de los nuevos Presupuestos Generales del Estado de 2012. Es posible que la evolución del peso de la financiación de proyectos destinados al FIP cambie de dirección, debido a que se estime más urgente o prioritario hacer énfasis en ayuda de tipo humanitaria y productiva. 
En el caso de las ONGD, también están a la cabeza de la tendencia actual de llevar a cabo cada vez más proyectos de FIP, principalmente relativos en este caso a apoyar la demanda de buen gobierno que realizan los ciudadanos locales. Las principales carencias que hemos detectado son: (1) la falta de una visión corporativa sobre este tema; (2) el excesivo énfasis en formación, estudio y sensibilización, faltando frecuentemente en sus proyectos mecanismos explícitos de incidencia en la toma de decisiones políticas; (3) la falta de actividades transversales de FIP en todos sus proyectos; y (4) la falta aún frecuente de indicadores objetivos de resultados.

Hemos detectado también que algunas ONGD justifican su inacción en el terreno del FI basándose en que ya hay ONGD especializadas en esta área y que en muchos países (principalmente de América Latina) la legislación esta ya suficientemente desarrollada y sólo falta voluntad política para aplicarla. En nuestra opinión, estas justificaciones no son válidas, ya que, como se ha mencionado, el FIP es una cuestión transversal, necesaria para garantizar la sostenibilidad de cualquier tipo de proyecto, y porque uno de los campos del FIP donde es más necesario incidir es en el del control efectivo de la actuación por parte de los organismos públicos.

Por último, partiendo de todas estas carencias, añadimos seis recomendaciones que estimamos podrían mejorar notablemente el impacto de nuestra cooperación para el FIP:

1. Comenzar barriendo nuestra propia casa. Es decir, fortaleciendo las instituciones y capacidades de los agentes de la cooperación española, de cara a conseguir una gestión más transparente y enfocada a resultados de sus recursos.

2. Entender que para que las acciones de fortalecimiento de recursos organizativos tengan éxito, requieren previamente de la existencia de instituciones suficientemente propicias. Esto supone por ejemplo el no emprender acciones de formación ni de dotación de equipos, sin disponer previamente de un diagnóstico riguroso de los problemas institucionales de la organización receptora.

3. Incluir (de forma transversal) en los formularios de todos los proyectos de cooperación un apartado sobre fortalecimiento institucional.

4. Establecer una línea base y unas metas con indicadores objetivos de los resultados institucionales de partida y los esperados en todos los proyectos.

5. Las ONGD deben elaborar una política corporativa sobre cómo propiciar el FIP a través de todos sus proyectos y establecer de forma explícita en los formularios de sus proyectos específicos de apoyo a la demanda de buen gobierno, las actividades que se van a realizar para lograr pasar del 
estudio, la capacitación y/o la sensibilización, a la incidencia sobre la toma de decisiones políticas.

\section{REFERENCIAS BIBLIOGRÁFICAS}

ACEMOGLU, D; JOHNSON, S.; y ROBINSON, J. (2001): "The Colonial Origins of Comparative Development: an Empirical Investigation" en American Economic Review, 91: pp, (1369-1401).

BANDEIRA, P. (2012): "Eficacia y Derechos Humanos en la Asignación de la Ayuda al Desarrollo del Gobierno de España" en Revista de Economía Mundial, en prensa.

BANDEIRA, P. (2009a): "El Desarrollo Institucional en el Contexto de la Ineficacia de la Ayuda: ¿Qué Podemos Hacer?" en Revista de Fomento Social 255: pp. (459-498).

BANDEIRA, P. (2009b): "Instituciones y Desarrollo Económico: Un Marco Conceptual" en Revista de Economía Institucional, 11(20): pp. (355-373).

BM (1998): Assessing Aid: What Works, What Doesn't, and Why, Washington D.C. y Oxford: Banco Mundial y Oxford University Press.

BRUNETI, A.; y WEDER, B. (2003): "A Free Press is Bad News for Corruption" en Journal of Public Economics, 87: pp. (1801-1824).

CE (2006): Governance in the European Consensus on Development: Towards a Harmonized Approach within the European Union, Bruselas: Comisión Europea 421 final.

COMMISSION ON GROWTH AND DEVELOPMENT (2008): The Growth Report: Strategies for Sustained Growth and Inclusive Development, Washington D.C.: Banco Mundial.

DEL ÁlAMO, A.; GUIJARRO, T.; y VIÑUALES, V. (1998): Informe de la evaluación del proyecto de Fortalecimiento Municipal y Saneamiento ambiental de la municipalidad de Flores, Guatemala. Madrid: Dirección General de Planificación y Evaluación de Políticas para el Desarrollo. Ministerio de Asuntos Exteriores y de Cooperación.

DFID (2006): White Paper on Eliminating World Poverty: Making Governance Work for the Poor, Londres: Department For International Development.

DGPOLDE (2011): Seguimiento del Plan Anual de Cooperación Internacional 2010, Madrid: Dirección General de Planificación y Evaluación de Políticas para el Desarrollo. Ministerio de Asuntos Exteriores y de Cooperación.

DGPOLDE (2010): Seguimiento del Plan Anual de Cooperación Internacional (PACI) 2009, Madrid: Dirección General de Planificación y Evaluación de Políticas para el Desarrollo. Ministerio de Asuntos Exteriores y de Cooperación. 
DGPOLDE (2002): Evaluación del Proyecto DRI Cotacachi, Madrid: Dirección General de Planificación y Evaluación de Políticas para el Desarrollo. Ministerio de Asuntos Exteriores y de Cooperación.

DGPOLDE (2000): El Programa de Cooperación Interuniversitaria en lberoamérica, Madrid: Dirección General de Planificación y Evaluación de Políticas para el Desarrollo. Ministerio de Asuntos Exteriores y de Cooperación.

DGPOLDE (1999): Evaluación del instrumento Fondo de Ayuda al Equipamiento, Madrid: Dirección General de Planificación y Evaluación de Políticas para el Desarrollo. Ministerio de Asuntos Exteriores y de Cooperación.

EASTERLY, W.; y LEVINE, R. (2003): "Tropics, germs and crops: how endowments influence economic development" en Journal of Monetary Economics, 50(1): pp. (3-39).

GOBIERNO DE ESPAÑA (2009): Plan Director de la Cooperación Española 2009-2012, Madrid: Gobierno de España.

LA PORTA, R.; LÓPEZ DE SILANES, F.; POP-ELECHES, C.; y SHLEIFER, A. (2004): "Judicial Checks and Balances" en Journal of Political Economy, 112: pp. (445-470).

NORRIS, P. (2007): Driving Democracy: Do Power-Sharing Institutions Work? Cambridge: Cambridge University Press.

NORTH, D. (1990): Institutions, Institutional Change and Economic Development, Cambridge: Cambridge University Press.

OCDE (2008): Agenda de Accra para Acción, París: Organización para la Cooperación y el Desarrollo Económico.

OCDE (2005): Declaración de París sobre la Eficacia de la Ayuda al Desarrollo, París: Organización para la Cooperación y el Desarrollo Económico.

PNUD (1997): Governance for Sustainable Human Development,. Nueva York: Programa de Naciones Unidas para el Desarrollo.

RAUCH, J.; y EVANS, P. (2000); "Bureaucratic Structure and Bureaucratic Performance in Less Developed Countries", en Journal of Public Economics, 75: pp. (49-71).

RODRIK, D.; SUBRAMANIAN, A.; y TREBBI, F. (2004): "Institutions Rule: the Primacy of Institutions over Geography and Integration in Economic Development" en Journal of Economic Growth, 9: pp. (131-165).

SEINTEX (2002): Evaluación del Proyecto de Reforma Judicial en la República de Bolivia. Madrid: Dirección General de Planificación y Evaluación de Políticas para el Desarrollo. Ministerio de Asuntos Exteriores y de Cooperación.

UIM (2005): Evaluación ex-post del programa de desarrollo local y fortalecimiento municipal de Honduras PRODEMHON. Madrid: Dirección General de Planificación y Evaluación de Políticas para el Desarrollo. Ministerio de Asuntos Exteriores y de Cooperación. 
USAID (2008): "Democracy and Governance". 12 de febrero de 2012. Disponible en http://www.usaid.gov/our_work/democracy_and_governance/ [10 de mayo de 2012] 


\section{ANEXO}

\section{Subsetores de la AOD considerados como FIP}

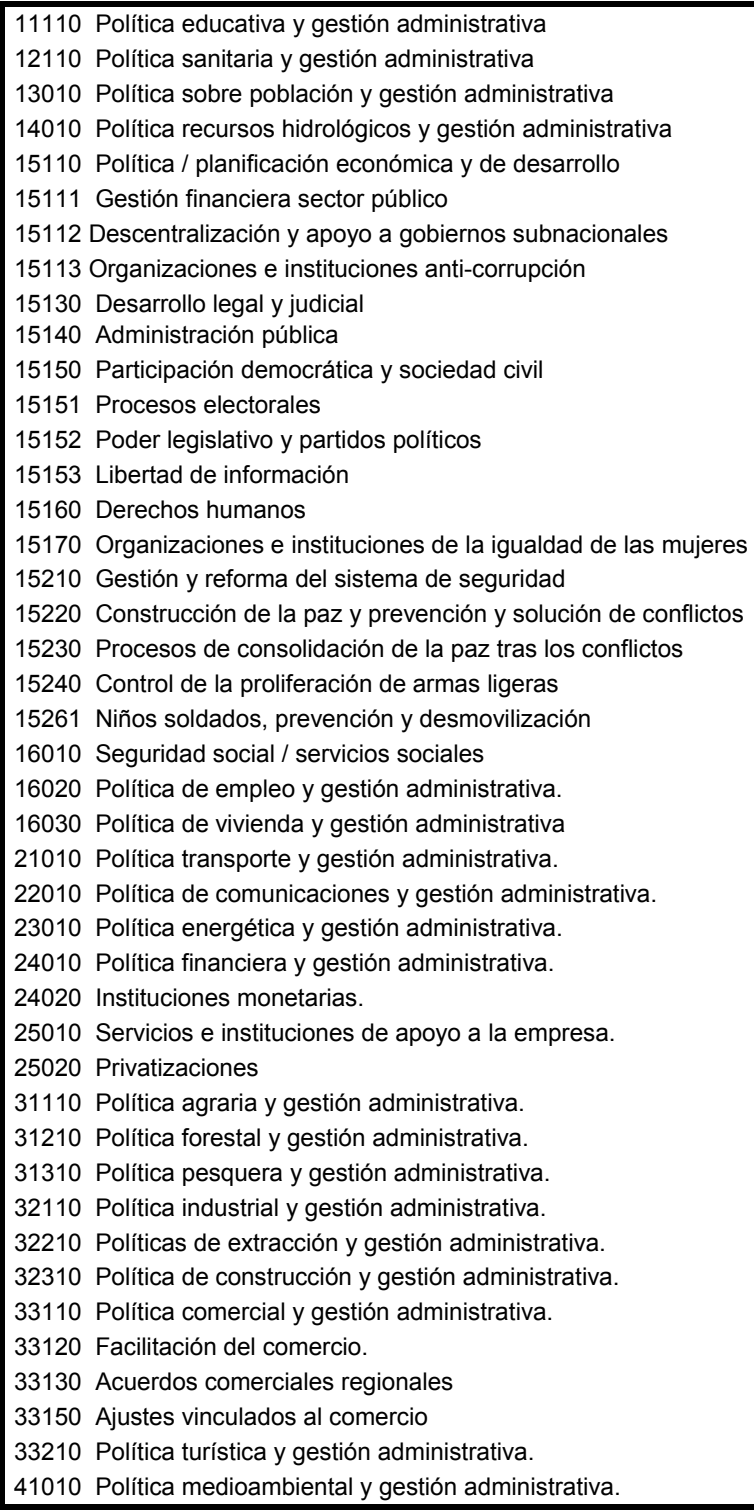

Fuente: Elaboración propia a partir de la clasificación de tipos de AOD de la OCDE. 
